Original article

\title{
Diastolic Function Is Impaired in Patients With Prehypertension: Data From the EPIPorto Study
}

\author{
Ricardo Ladeiras-Lopes, ${ }^{\mathrm{a}, \mathrm{b}, \mathrm{c}, \diamond, *}$ Ricardo Fontes-Carvalho, ${ }^{\mathrm{a}, \mathrm{b}, \mathrm{c}, \diamond}$ Eduardo M. Vilela, ${ }^{\mathrm{b}}$ Paulo Bettencourt, ${ }^{\mathrm{c}, \mathrm{d}}$ \\ Adelino Leite-Moreira, ${ }^{\mathrm{a}, \mathrm{c}, \mathrm{e}}$ and Ana Azevedo ${ }^{\mathrm{a}, \mathrm{f}, \mathrm{g}}$ \\ a Departamento de Cirurgia e Fisiologia, Faculdade de Medicina, Universidade do Porto, Porto, Portugal \\ ${ }^{\mathrm{b}}$ Departamento de Cardiologia, Centro Hospitalar de Gaia/Espinho, Vila Nova de Gaia, Portugal \\ ${ }^{\mathrm{c}}$ Unidade de Investigação Cardiovascular, Universidade do Porto, Porto, Portugal \\ ${ }^{\mathrm{d}}$ Departamento de Medicina, Faculdade de Medicina, Universidade do Porto, Porto, Portugal \\ e Departamento de Cirurgia Cardiotorácica, Centro Hospitalar São João, Porto, Portugal \\ ${ }^{\mathrm{f}}$ Departamento de Epidemiologia Clínica, Medicina Preditiva e Saúde Publica, Faculdade de Medicina, Universidade do Porto, Porto, Portugal \\ ${ }^{\mathrm{g}}$ Epidemiology Research Unit (EPIUnit) - Instituto de Saúde Pública, Universidade do Porto, Porto, Portugal
}

Article history:

Received 7 June 2017

Accepted 2 November 2017

\section{Keywords:}

Prehypertension

Hypertension

Diastolic function

\begin{abstract}
A B S T R A C T
Introduction and objectives: Hypertension causes subclinical changes in left ventricular structure and function, namely diastolic dysfunction. Diastolic dysfunction is a predictor of heart failure, being involved in the association between hypertension and heart failure with preserved ejection fraction. We aimed to determine whether patients with prehypertension have early changes in diastolic function in a large community-based cohort of asymptomatic adults.

Methods: A cross-sectional evaluation was performed of a community-based cohort consisting of 925 adults, aged 45 years or older, without known cardiovascular disease. All participants underwent detailed clinical and echocardiographic examination. The participants were categorized according to the European guidelines for the classification of office blood pressure (BP) levels as optimal, prehypertensive (normal and high-normal categories), and hypertensive. Diastolic function was evaluated by echocardiography using e' velocities and E/e' ratio. Diastolic dysfunction was defined using the 2016 ASE/EACVI Joint Recommendations and a 2017 clinically-oriented algorithm.

Results: In this cohort $(61.5 \pm 10.5$ years; $37 \%$ men), prehypertension was present in $30.4 \%$ and hypertension in $51.0 \%$. Using optimal BP as the reference, there was a progressive decrease of e' velocity in prehypertensive and hypertensive individuals $(12.2 \pm 3.5 \mathrm{vs} 11.3 \pm 3.1 \mathrm{vs} 9.6 \pm 2.9 \mathrm{~cm} / \mathrm{s}$, respectively; $P$ for trend $<.001)$. After multivariable adjustment, both BP categories were independent predictors of a lower e' velocity ( $\beta=-0.56, P=.035$ for prehypertension and $\beta=-1.08, P<.001$ for hypertension).

Conclusions: In this large community-based cohort, adults with prehypertension already showed impaired cardiac relaxation before the onset of hypertension.
\end{abstract}

(c) 2017 Sociedad Española de Cardiología. Published by Elsevier España, S.L.U. All rights reserved.

\section{La función diastólica se altera en pacientes con prehipertensión: datos del estudio EPIPorto}

R E S U M E N

Introducción y objetivos: La hipertensión causa cambios subclínicos en la estructura y la función del ventrículo izquierdo, es decir, disfunción diastólica. La disfunción diastólica es un predictor de insuficiencia cardiaca, pues participa en la asociación entre hipertensión e insuficiencia cardiaca con fracción de eyección conservada. El objetivo es evaluar en una gran cohorte poblacional de adultos asintomáticos si los pacientes con prehipertensión tienen cambios precoces en la función diastólica. Métodos: Se evaluó de manera transversal una cohorte poblacional consistente en 925 adultos de 45 años o más sin enfermedad cardiovascular conocida. Todos los participantes se sometieron a un examen clínico y ecocardiográfico detallado. Se clasificó a los participantes, según las guías europeas para la clasificación de la presión arterial (PA) en la consulta, como óptima, prehipertensión (normal y normal-alta) e hipertensión. La función diastólica se evaluó mediante ecocardiografía usando las velocidades de e' y la razón E/e'. La disfunción diastólica se definió utilizando las recomendaciones conjuntas de ASE/EACVI de 2016 y un algoritmo de orientación clínica de 2017.
Palabras clave:

Prehipertensión

Función diastólica

\footnotetext{
* Corresponding author: Departamento de Cardiologia, Centro Hospitalar de Gaia/Espinho, Rua Conceicao Fernandes, 4434-502 Vila Nova de Gaia, Portugal.

E-mail address: ricardoladeiraslopes@gmail.com (R. Ladeiras-Lopes)

$\diamond$ Both authors equally contributed to this work.
} 
Resultados: En esta cohorte (61,5 $\pm 10,5$ años; el 37\% varones), tenía prehipertensión el 30,4\% e hipertensión el 51,0\%. Se utilizó la PA óptima como referencia, y se observó una disminución progresiva de la velocidad e' en los individuos prehipertensos e hipertensos (12,2 $\pm 3,5$ frente a 11,3 $\pm 3,1$ frente a 9,6 \pm $2,9 \mathrm{~cm} / \mathrm{s}$ respectivamente; $\mathrm{p}$ de tendencia $<0,001$ ). Después del ajuste multivariable, ambas categorías de PA fueron predictoras independientes de una menor velocidad e' (prehipertensión, $\beta=-0,56 ; p=0,035$; hipertensión, $\beta=-1,08 ; \mathrm{p}<0,001$ ).

Conclusiones: En esta cohorte poblacional, los adultos con prehipertensión mostraron una relajación cardiaca alterada antes del inicio de la hipertensión.

(c) 2017 Sociedad Española de Cardiología. Publicado por Elsevier España, S.L.U. Todos los derechos reservados.

\author{
Abbreviations \\ BP: blood pressure \\ DBP: diastolic blood pressure \\ DD: diastolic dysfunction \\ PP: pulse pressure \\ SBP: systolic blood pressure
}

\section{INTRODUCTION}

Arterial hypertension is an important independent risk factor for cardiovascular disease and the single largest contributor to global mortality. ${ }^{1}$ In hypertension, subclinical organ damage represents an intermediate stage in the cardiovascular continuum, being associated with cardiovascular events. ${ }^{2}$ Therefore, current European guidelines recommend a holistic approach to the hypertensive patient, which includes the assessment of organ damage (cardiac, vascular, renal, and ophthalmic) as part of the diagnostic workup of these patients. ${ }^{3}$ Regarding cardiac involvement, hypertension can cause changes in both structure and function, ${ }^{4}$ particularly left ventricular hypertrophy and impaired diastolic function. ${ }^{5}$ Both have been shown to be independently associated with mortality and cardiovascular events. ${ }^{6}$

Diastolic dysfunction (DD) is prevalent among the general population, affecting $20 \%$ to $30 \%$ of individuals s $^{7,8}$ and is strongly associated with aging, ${ }^{9}$ obesity, ${ }^{8}$ insulin resistance, ${ }^{10}$ and hypertension. ${ }^{11}$ Although usually subclinical, ${ }^{11} \mathrm{DD}$ is an important predictor of heart failure, especially of heart failure with preserved ejection fraction, ${ }^{12}$ and of long-term mortality. ${ }^{13}$ These findings support the role of DD as an intermediate step between hypertension and blood pressure (BP). ${ }^{11}$ The importance of assessing diastolic function in hypertension is acknowledged in recent recommendations, which state that evaluation of diastolic parameters should be an integral part of the echocardiogram of the hypertensive patient. ${ }^{14}$ However, the recently updated 2016 Joint Guideline of the American Society of Echocardiography and the European Association of Cardiovascular Imaging ("50\% rule") ${ }^{15}$ has been criticized due to the absence of validation data to support its use and the potential for underdiagnosing DD, and new diagnostic algorithms have been proposed. ${ }^{16}$

Observational studies have shown that the risk of cardiovascular events is directly related to systolic BP (SBP) and diastolic $\mathrm{BP}$ (DBP) values, with a progressively higher risk for BP levels over $115 \mathrm{mmHg}$ of SBP and $75 \mathrm{mmHg}$ of DBP. ${ }^{17}$ However, although hypertension is clearly associated with $\mathrm{DD}$, few studies have assessed whether "prehypertensive patients" (BP 120-139/ $80-89 \mathrm{mmHg}$ ) already have subclinical impaired diastolic function. ${ }^{18}$ Moreover, few studies have assessed the impact of different BP parameters on diastolic function. ${ }^{19}$

In this study we aimed to assess: a) whether individuals in the prehypertensive range already have changes in diastolic function; and $b$ ) the association between diastolic function and different BP parameters, such as SBP, DBP, and pulse pressure (PP).

\section{METHODS}

\section{Study Sample}

This was a cross-sectional study including participants selected within the first follow-up of a cohort representative at baseline of the adult population of Porto, Portugal-the EPIPorto cohort study. From 1999 to 2003 the cohort assembly was made by random-digit dialing using households as the sampling frame, followed by random selection of 1 person aged 18 years or older in each household. Refusals were not substituted within the same household. The proportion of participation was 70\%. At baseline, 2485 participants were recruited. Between October 2006 and July 2008 , participants aged 45 years or over were eligible for a systematic evaluation of parameters of cardiac structure and function, which included a cardiovascular clinical history, physical examination, detailed anthropometric evaluation, collection of a fasting blood sample, and a transthoracic echocardiogram (Figure 1). Among 2048 cohort members in the eligible age range at this time, 134 (6.5\%) had died, 198 (9.7\%) refused to be re-evaluated, and 580 (28.3\%) were lost to follow-up (unreachable by telephone or post). Of the 1136 participants who underwent cardiac evaluation, we excluded from this study those with previous myocardial infarction, percutaneous or surgical revascularization, prior cardiac surgery or moderate to severe valvular heart disease, atrial fibrillation, abnormal left ventricle ejection fraction and symptoms of angina, or heart failure (Figure 1). Written informed consent was obtained from all the individuals and the study was approved by the local ethics committee.

\section{Clinical Variable Definitions}

Participants were instructed to take their usual medication and abstain from alcohol, tea, coffee, smoking, and exercise in the 30 minutes before the medical evaluation and BP measurement. Systolic BP was identified by phase I Korotkoff sound and DBP by phase V. Two measurements of BP separated by at least 5 minutes were taken, on a single occasion, in the sitting position, with an ERKA 300 sphygmomanometer after a 10-minute rest, with no tight clothes, on the right upper arm, and at heart level. The mean was considered and when the difference was larger than $5 \mathrm{mmHg}$ for systolic or DBP a third measurement was taken and the mean of the 2 closest values was registered. According to the current guidelines, ${ }^{3}$ participants were divided into groups according to their BP levels: "optimal BP" (SBP $<120 \mathrm{mmHg}$ and DBP $<80 \mathrm{mmHg}$ ); "prehypertension" (SBP $120-139 \mathrm{mmHg}$ or DBP $80-89 \mathrm{mmHg}$ ); "hypertension" (SBP $\geq 140 \mathrm{mmHg}$ or DBP $\geq 90 \mathrm{mmHg}$ or use of antihypertensive medication). 


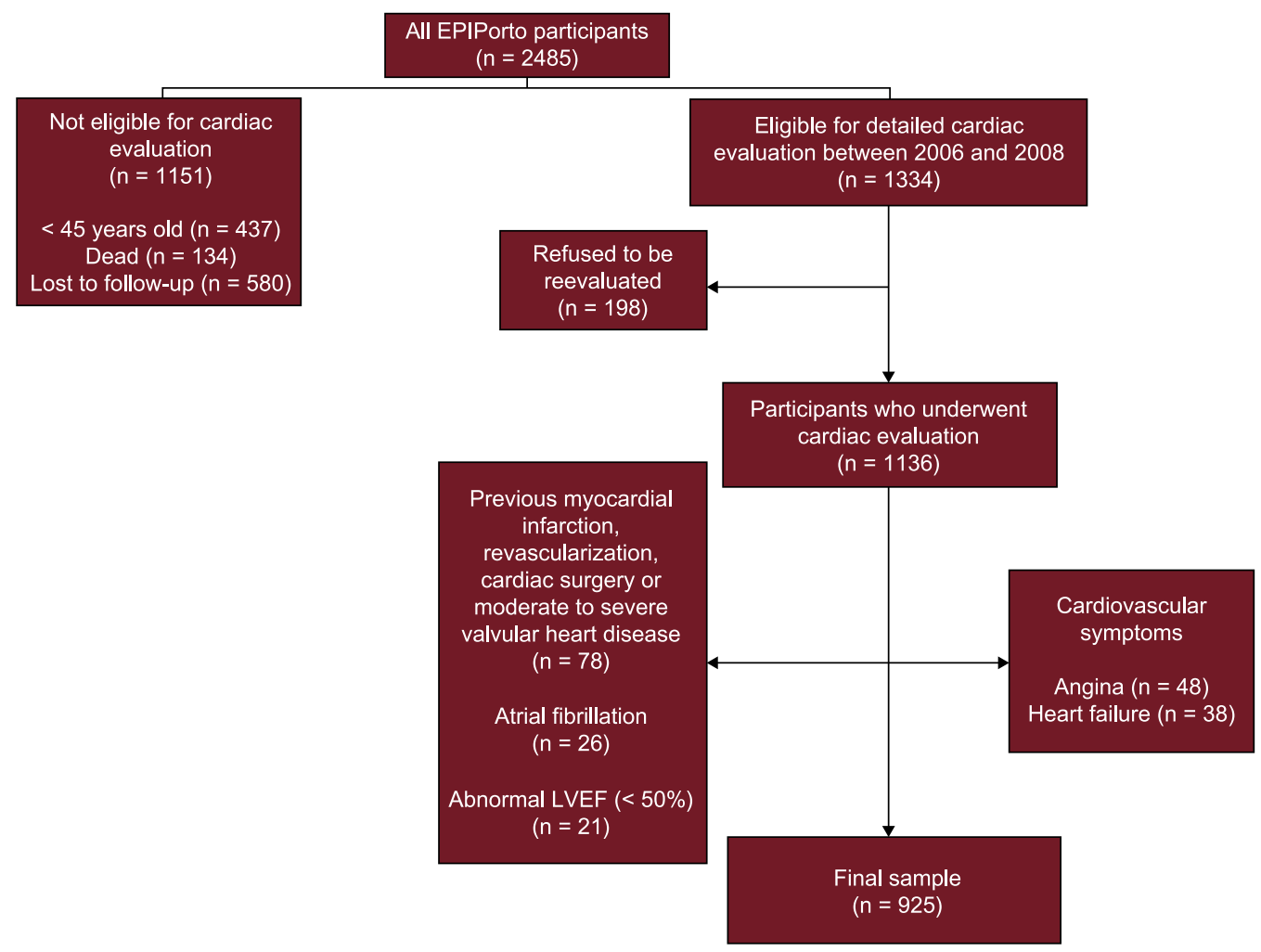

Figure 1. Flowchart of EPIPorto cohort study participants who were included in this study. LVEF, left ventricular ejection fraction.

Diabetes was defined as fasting blood glucose $\geq 126 \mathrm{mg} / \mathrm{dL}$ or the patient's self-reported history of diabetes or use of diabetes medications.

\section{Analytical and Anthropometric Evaluation}

A fasting venous blood sample was obtained in the morning for measurement of glucose, total cholesterol, LDL, HDL, and triglycerides.

Anthropometric measurements were performed after an overnight fast, with the participant wearing light clothing and no footwear. Body weight was measured to the nearest $0.1 \mathrm{~kg}$ using a digital scale, and height was measured to the nearest centimeter in the standing position using a wall stadiometer. Body mass index was calculated as weight $(\mathrm{kg})$ divided by squared height $\left(\mathrm{m}^{2}\right)$. Overweight was defined as body mass index $\geq 25$ and below $30 \mathrm{~kg} / \mathrm{m}^{2}$, and obesity as body mass index $\geq 30 \mathrm{~kg} / \mathrm{m}^{2}$.

\section{Echocardiography Data}

All echocardiographic studies were acquired using the same equipment (Hewlett-Packard Sonos 5500) and immediately after assessment of BP. Images were stored on videotape for subsequent offline analysis by 2 experienced cardiologists, blinded to clinical data. Cardiac chamber dimensions, volumes and left ventricular mass were measured following the standard recommendations ${ }^{20}$ and indexed to body surface area. Systolic function was evaluated by ejection fraction calculation using the modified biplane Simpson's rule. Diastolic function was assessed according to the 2016 Joint Guidelines on Diastolic Function Evaluation ${ }^{15}$ with measurement of mitral inflow velocities (E-wave, A-wave, E/A ratio) and E-wave deceleration time and isovolumetric relaxation time using pulsed-wave Doppler in the apical 4-chamber view.
Velocities were recorded at end-expiration and averaged over 3 consecutive cardiac cycles. Pulsed-wave tissue Doppler velocities were acquired at end-expiration, in the apical 4-chamber view, at the lateral side of the mitral annulus, measuring early diastolic $\left(\mathrm{e}^{\prime}\right)$ and late diastolic $\left(a^{\prime}\right)$ velocities and estimating the $E / e^{\prime}$ ratio accordingly.

The main definition of DD used in the study followed the recommendations in the 2016 consensus document, ${ }^{15}$ where DD was defined if more than 2 of the following were present: lateral E/e' ratio $>13$, lateral e' velocity $<10 \mathrm{~cm} / \mathrm{s}$, left atrial maximum volume index $>34 \mathrm{~mL} / \mathrm{m}^{2}$, and peak tricuspid regurgitation velocity $>2.8 \mathrm{~m} / \mathrm{s}$. Diastolic function was classified as normal if less than 2 were present and indeterminate if 2 of the 4 conditions were present (Figure 2). In addition, considering the limitations of the 2016 recommendations, we also included data using 2 additional DD definitions: the previous European Association of Cardiovascular Imaging/American Society of Echocardiography (EACVI/ASE) consensus from $2009^{21}$ and a recently published clinically-oriented algorithm to assess DD and left ventricle filling pressure (see Figure 2 for a detailed description of the algorithm). ${ }^{16}$

\section{Statistical Analysis}

Continuous variables are reported as mean \pm standard deviation or median [interquartile range]. Discrete variables are given in frequency and percentage. ANOVA or the chi-squared test were used to test for significant differences between demographic and clinical variables across BP groups (optimal, prehypertension, hypertension).

The Spearman rank correlation was used to assess the relationship between SBP, DBP, and PP and diastolic indices. The "nptrend" command in Stata was used to perform a nonparametric test of trend for the ranks across ordered groups.

To assess whether the categories of BP were associated with lateral E' and $\mathrm{E} / \mathrm{E}^{\prime}$ ratio, we used multivariable linear regression 


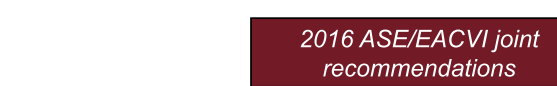

recommendations

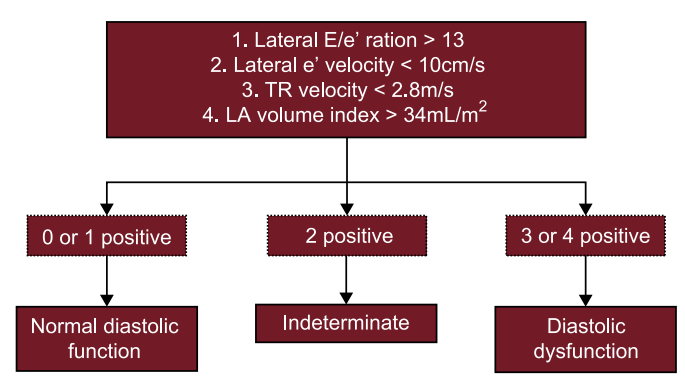

2017 JACC clinically-oriented algorithm

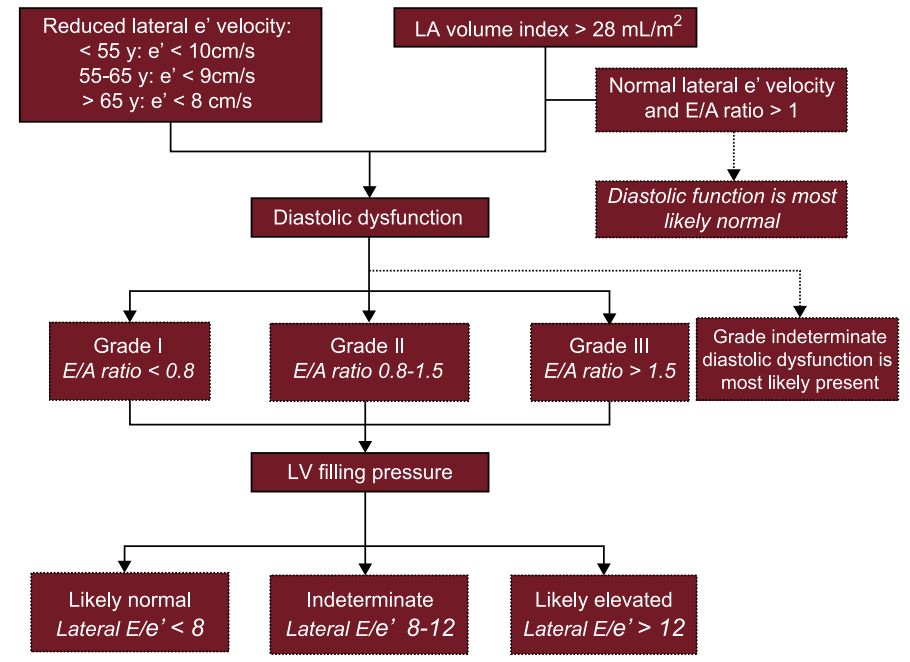

Figure 2. A classification scheme for characterization of diastolic function according to the 2016 ASE/EACVI Joint Recommendations and 2017 clinically-oriented algorithm. ASE/EACVI, American Society of Echocardiography/European Association of Cardiovascular Imaging; LA, left atrial; LV, left ventricle; TR, tricuspid regurgitation.

analysis including age, sex, body mass index, presence of diabetes, and BP category in the model, the latter as a categorical variable with "optimal BP" as the reference category. For evaluation of the association between DD and BP variables, we used Firth-type penalized likelihood logistic regression analysis, to correct for small-sample bias in beta coefficient estimation. McFadden's R-squared was used to assess the goodness-of-fit of the final regression models. Cases of indeterminate diastolic function $(n=134)$ were excluded from this analysis.

Considering the mean e' velocities in the groups of interest (optimal BP, prehypertension, and hypertension), assuming a within-group variance of 12 and the number of individuals in each group of interest, we had a power of approximately $100 \%$ to detect a significant difference in e' velocities with a type $\mathrm{I}$ error probability below $5 \%$.

All statistical analyses were conducted using Stata 14.0 for Mac (StataCorp, College Station, Texas, United States).

\section{RESULTS}

The final analysis included 925 participants with a mean age of $61.5 \pm 10.5$ years $(37 \%$ men). The prevalence of hypertension was 51.0\% (472 individuals) and 30.4\% (281 individuals) were prehypertensive (normal or high-normal BP categories). The clinical, anthropometric, analytical and echocardiographic characteristics of the study sample are shown in Table 1. Individuals with prehypertension and hypertension showed an increased left ventricular mass index and the latter was an independent predictor of e' velocity and E/e' ratio. Regarding antihypertensive therapy, $22.2 \%$ were taking a renin-angiotensin axis modifier, 5.5\% a calcium channel antagonist and $10.4 \%$ were on diuretics.

According to the 2016 ASE/EACVI Joint Recommendations, diastolic function was considered normal in 783 individuals (84.7\%), abnormal in 8 (0.9\%) and indeterminate in 134 (14.5\%). However, when the 2017 clinically-oriented algorithm was used, the prevalence of DD was $49.2 \%$ : $16.2 \%$ had grade I DD, $5.2 \%$ had grade II, and $0.3 \%$ grade III DD. In 254 individuals, DD was graded as indeterminate.

\section{Association Between Different Blood Pressure Parameters and Diastolic Function}

Systolic BP values correlated with diastolic function parameters, showing a negative correlation with e' velocity (Spearman's $\rho$ $=-0.3 ; P<.001)$ and a positive correlation with $\mathrm{E} / \mathrm{e}^{\prime}$ ratio (Spearman's $\rho=0.2 ; P<.001$ ), as detailed in Figure 3. After adjusting for age, sex, body mass index, and diabetes, we observed that for each $10 \mathrm{mmHg}$ increase in SBP there was a $0.2 \mathrm{~cm} / \mathrm{s}$ decrease in e' velocity and a 0.1 increase in the $\mathrm{E} / \mathrm{e}^{\prime}$ ratio, as detailed in Table 2. Systolic BP was not associated with DD using the more stringent 2016 criteria. However, each $10 \mathrm{mmHg}$ increase in SBP was associated with a $20 \%$ increase in the adjusted odds for DD according to the 2017 clinically-oriented algorithm.

As shown in Figure 3, there was also an inverse correlation between DBP and e' velocity (Spearman's $\rho=-0.1 ; P=.01$ ), but not with $\mathrm{E} / \mathrm{e}$ ' ratio (Spearman's $\rho=-0.1 ; P=.23$ ). In the multivariable analysis, for each $10 \mathrm{mmHg}$ increase in DBP we observed a $0.3 \mathrm{~cm} / \mathrm{s}$ decrease in e' velocity, and a $30 \%$ increase in the adjusted odds for DD according to the 2017 algorithm (no significant association was found when using the 2016 joint criteria).

PP was inversely correlated with the e' velocity (Spearman's $\rho=$ $-0.4 ; P<.001)$ and positively correlated with the $\mathrm{E} / \mathrm{E}^{\prime}$ ratio (Spearman's $\rho=0.3 ; P<.001$ ), as detailed in Figure 3. In the multivariable regression analyses, $\mathrm{PP}$ was significantly associated with E/e' ratio (each $10 \mathrm{mmHg}$ increase in PP was associated with a 0.2 increase in the E/e' ratio) but not with e' velocity. PP was associated with an increased odds of DD when we used both the 2016 criteria (odds ratio [OR], 1.07; $\mathrm{P}<.001)$ and 2017 algorithm (OR, 1.01; $P=.013)$.

Higher SBP and PP were associated with an increase in left atrial volume index in the univariate analyses, but not DBP. However, after adjustment for age, sex, body mass index and diabetes, only PP remained a significant predictor of left atrial volume index.

\section{Diastolic Function Parameters in Different Categories of Blood Pressure}

When compared with individuals with optimal BP, prehypertensive and hypertensive participants showed a progressive 
Table 1

Study Participant Characteristics, According to Blood Pressure Levels

\begin{tabular}{|c|c|c|c|c|c|}
\hline & $\begin{array}{l}\text { Total } \\
(\mathrm{n}=925)\end{array}$ & $\begin{array}{l}\text { Optimal BP } \\
(\mathrm{n}=172)\end{array}$ & $\begin{array}{l}\text { Prehypertension } \\
(\mathrm{n}=281)\end{array}$ & $\begin{array}{l}\text { Hypertension } \\
(\mathrm{n}=472)\end{array}$ & $P$ \\
\hline Age, $y$ & $61.5 \pm 10.5$ & $56.5 \pm 10.0$ & $58.7 \pm 9.8$ & $65.0 \pm 9.8$ & $<.001$ \\
\hline Male sex & $346(37)$ & $41(24)$ & $132(47)$ & $173(37)$ & $<.001$ \\
\hline \multicolumn{6}{|l|}{ Cardiovascular risk factors } \\
\hline Diabetes & $99(11)$ & $6(3)$ & $17(6)$ & $76(16)$ & $<.001$ \\
\hline Total cholesterol, mg/dL & $220.6 \pm 53.1$ & $222.3 \pm 72.2$ & $220.7 \pm 58.9$ & $220.0 \pm 39.7$ & .881 \\
\hline LDL-C, mg/dL & $134.8 \pm 53.3$ & $139.2 \pm 74.7$ & $136.3 \pm 61.2$ & $132.3 \pm 35.9$ & .305 \\
\hline HDL-C, mg/dL & $61.9 \pm 45.9$ & $67.7 \pm 72.7$ & $62.2 \pm 57.9$ & $59.6 \pm 13.7$ & .141 \\
\hline Triglycerides, mg/dL & $152.8 \pm 468.1$ & $164.9 \pm 757.9$ & $166.0 \pm 601.0$ & $140.6 \pm 78.6$ & .724 \\
\hline BMI, $\mathrm{kg} / \mathrm{m}^{2}$ & $27.3 \pm 4.6$ & $25.6 \pm 4.3$ & $26.9 \pm 4.6$ & $28.2 \pm 4.5$ & $<.001$ \\
\hline $\mathrm{SBP}, \mathrm{mmHg}$ & $132.5 \pm 19.4$ & $109.3 \pm 6.5$ & $127.4 \pm 7.5$ & $144.1 \pm 18.5$ & $<.001$ \\
\hline DBP, mmHg & $78.4 \pm 11.2$ & $67.1 \pm 6.2$ & $78.3 \pm 8.0$ & $82.6 \pm 11.4$ & $<.001$ \\
\hline Pulse pressure, $\mathrm{mmHg}$ & $52.1 \pm 16.7$ & $41.7 \pm 10.0$ & $47.2 \pm 12.8$ & $58.8 \pm 17.8$ & $<.001$ \\
\hline \multicolumn{6}{|l|}{ Echocardiographic data } \\
\hline Septum, mm & $8.6 \pm 1.4$ & $7.9 \pm 1.1$ & $8.4 \pm 1.2$ & $9.0 \pm 1.5$ & $<.001$ \\
\hline Posterior wall, mm & $7.9 \pm 1.2$ & $7.2 \pm 1.0$ & $7.7 \pm 1.1$ & $8.2 \pm 1.3$ & $<.001$ \\
\hline LV mass index, $\mathrm{g} / \mathrm{m}^{2}$ & $78.3 \pm 18.8$ & $70.3 \pm 13.8$ & $75.2 \pm 17.1$ & $83.2 \pm 19.9$ & $<.001$ \\
\hline LA volume index, $\mathrm{mL} / \mathrm{m}^{2}$ & $28.2 \pm 9.5$ & $26.9 \pm 9.2$ & $27.7 \pm 8.6$ & $29.0 \pm 10.0$ & .023 \\
\hline LVED volume index, $\mathrm{mL} / \mathrm{m}^{2}$ & $65.6 \pm 15.9$ & $64.9 \pm 16.0$ & $65.8 \pm 14.8$ & $65.8 \pm 16.5$ & .800 \\
\hline LVES volume index, $\mathrm{mL} / \mathrm{m}^{2}$ & $26.4 \pm 8.8$ & $26.1 \pm 8.5$ & $26.5 \pm 8.8$ & $26.5 \pm 8.8$ & .835 \\
\hline Ejection fraction, \% & $60.7 \pm 6.1$ & $60.9 \pm 5.7$ & $60.9 \pm 6.3$ & $60.5 \pm 6.0$ & .594 \\
\hline E-wave, $\mathrm{cm} / \mathrm{s}$ & $71.6 \pm 15.3$ & $73.3 \pm 15.6$ & $71.1 \pm 14.9$ & $71.2 \pm 15.4$ & .274 \\
\hline A-wave, $\mathrm{cm} / \mathrm{s}$ & $78.2 \pm 19.9$ & $68.9 \pm 19.5$ & $72.5 \pm 16.8$ & $85.0 \pm 19.3$ & $<.001$ \\
\hline E/A ratio & $0.96 \pm 0.30$ & $1.12 \pm 0.33$ & $1.03 \pm 0.31$ & $0.87 \pm 0.26$ & $<.001$ \\
\hline Deceleration time, ms & $236.3 \pm 54.1$ & $226.6 \pm 51.1$ & $228.7 \pm 47.7$ & $244.4 \pm 57.6$ & $<.001$ \\
\hline IVRT, ms & $91.3 \pm 15.8$ & $87.9 \pm 12.3$ & $91.1 \pm 15.2$ & $92.7 \pm 17.0$ & .003 \\
\hline
\end{tabular}

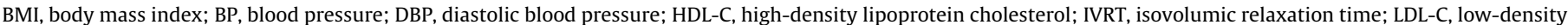
lipoprotein cholesterol; LA, left atria; LV, left ventricle; LVED, left ventricle end-diastolic; LVES, left ventricle end-systolic; SBP, systolic blood pressure.

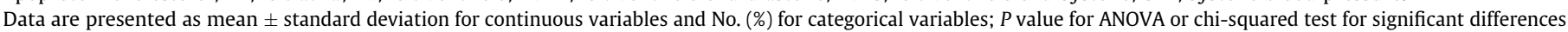
between BP groups.
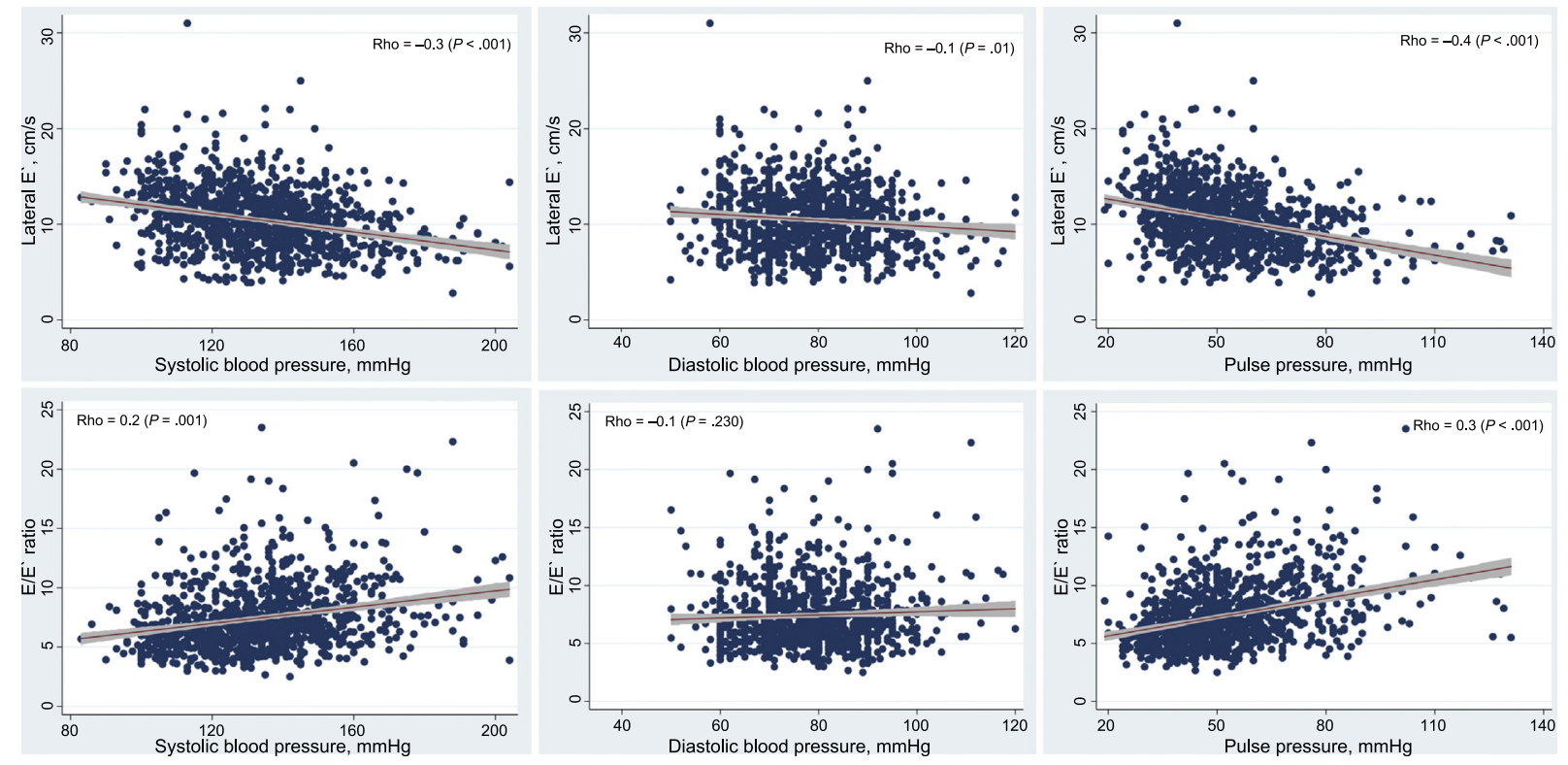

Figure 3. Correlations between blood pressure variables (systolic blood pressure, diastolic blood pressure, and pulse pressure) and diastolic function parameters.

deterioration in diastolic function parameters ( $P$ for trend $<.001)$. Prehypertension was associated with lower E' velocity (11.3 \pm $3.1 \mathrm{~cm} / \mathrm{s}$ vs $12.2 \pm 3.5 \mathrm{~cm} / \mathrm{s}$ in individuals with optimal BP; $P=.003)$, which was even lower in those with hypertension $(9.6 \pm 2.9 \mathrm{~cm} / \mathrm{s}$ vs
$12.2 \pm 3.5 \mathrm{~cm} / \mathrm{s} ; P<.001)$, as depicted in Figure 4 . In the multivariable analysis, both prehypertension ( $\beta=-0.56 ; P=.035$ ) and hypertension $(\beta=-1.08 ; P<.001)$ were associated with a significant decrease in the E' velocity, as detailed in Table 3 . 
Table 2

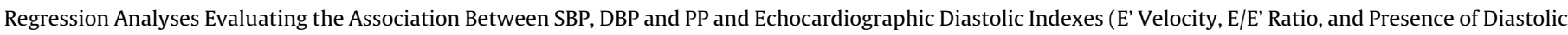
Dysfunction)

\begin{tabular}{|c|c|c|c|c|c|c|}
\hline & \multicolumn{3}{|c|}{ Univariable analysis } & \multicolumn{3}{|c|}{ Multivariable analysis } \\
\hline & $\beta$ coefficient & SE & $P$ & $\beta$ coefficient & SE & $P$ \\
\hline \multicolumn{7}{|l|}{ E'velocity } \\
\hline SBP (per mmHg) & -0.049 & 0.005 & $<.001$ & -0.015 & 0.005 & .003 \\
\hline DBP (per mmHg) & -0.030 & 0.010 & .001 & -0.031 & 0.008 & $<.001$ \\
\hline PP (per mmHg) & -0.065 & 0.006 & $<.001$ & -0.010 & 0.006 & .126 \\
\hline \multicolumn{7}{|l|}{ E/E' ratio } \\
\hline SBP (per mmHg) & 0.032 & 0.004 & $<.001$ & 0.013 & 0.004 & .004 \\
\hline DBP (per mmHg) & 0.009 & 0.008 & .238 & 0.009 & 0.007 & .225 \\
\hline PP (per mmHg) & 0.051 & 0.005 & $<.001$ & 0.020 & 0.005 & $<.001$ \\
\hline \multicolumn{7}{|l|}{ LA volume index } \\
\hline SBP (per mmHg) & 0.061 & 0.016 & $<.001$ & 0.032 & 0.018 & .065 \\
\hline DBP (per mmHg) & -0.016 & 0.028 & .567 & -0.017 & 0.029 & .559 \\
\hline \multirow[t]{2}{*}{$\mathrm{PP}$ (per mmHg) } & 0.124 & 0.018 & $<.001$ & 0.094 & 0.022 & $<.001$ \\
\hline & Odds ratio & SE & $P$ & Odds ratio & SE & $P$ \\
\hline \multicolumn{7}{|l|}{ Diastolic dysfunction } \\
\hline \multicolumn{7}{|c|}{2016 joint ASE/EACVI recommendations } \\
\hline SBP (per mmHg) & 1.05 & 0.016 & .002 & 1.03 & 0.017 & .108 \\
\hline DBP (per mmHg) & 0.98 & 0.032 & .447 & 0.99 & 0.032 & .658 \\
\hline PP (per mmHg) & 1.08 & 0.017 & $<.001$ & 1.07 & 0.018 & $<.001$ \\
\hline \multicolumn{7}{|c|}{2017 clinically-oriented algorithm } \\
\hline SBP (per mmHg) & 1.03 & 0.004 & $<.001$ & 1.02 & 0.004 & $<.001$ \\
\hline DBP (per mmHg) & 1.02 & 0.006 & $<.001$ & 1.03 & 0.007 & $<.001$ \\
\hline PP (per mmHg) & 1.04 & 0.005 & $<.001$ & 1.01 & 0.005 & .013 \\
\hline
\end{tabular}

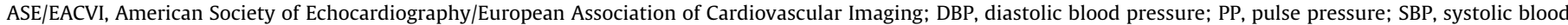
pressure; SE, standard error.

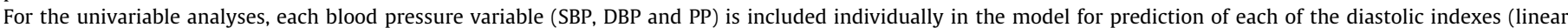
regression) and diastolic dysfunction (logistic regression).

In the multivariable analyses, age, sex, body mass index, and the presence of diabetes were included in the model, in addition to the blood pressure variable assessed in each regression equation. All multivariable models showed McFadden's R-squared between 0.2 and 0.4 , therefore providing good-fit models.
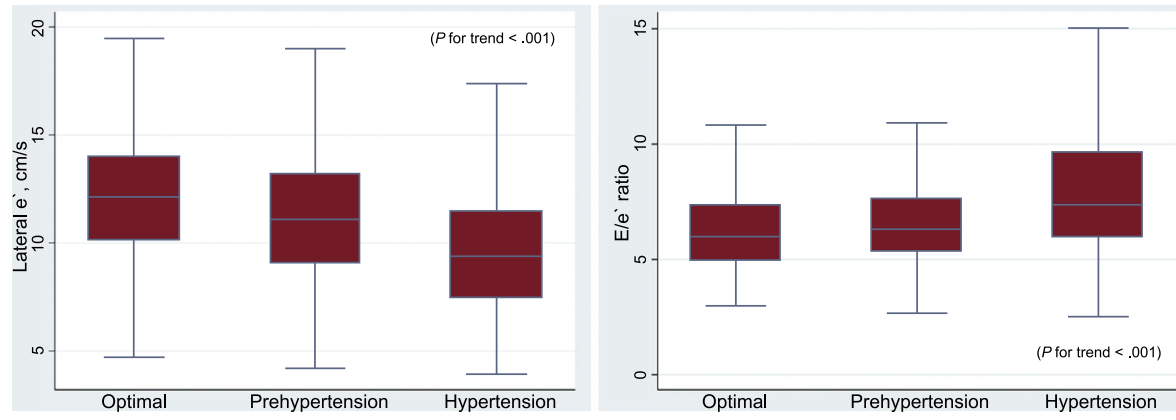

Figure 4. Diastolic function (e' velocity and E/e' ratio) according to blood pressure categories.

There was a significant trend toward a progressive increase in the E/e' ratio as BP levels increased $(6.4 \pm 2.1$ for optimal BP, $6.7 \pm$ 2.1 for prehypertension and $8.0 \pm 2.9$ for hypertensive individuals; $P$ for trend $<.001)$. However, after adjustment for age, sex, body mass index, and diabetes, only hypertension was significantly associated with the lateral E/e' ratio (Table 3).

According to the 2016 Joint Recommendations, DD was present in $0.8 \%$ of prehypertensive and $1.3 \%$ of hypertensive patients (Table 4). Using the less stringent 2017 algorithm, there was a progressive and significant increase in the prevalence of DD across BP categories, from $28 \%$ in individuals with optimal BP, $39 \%$ in prehypertension and 63\% in hypertension (Table 4). Furthermore, we found an increasing prevalence of likely elevated left ventricle filling pressures $(1 \%, 5 \%$, and $11 \%$ in the optimal, prehypertensive and hypertensive groups, respectively).

We found no significant association between BP categories and DD using the 2016 criteria ( 8 cases of DD). Prehypertension was significantly associated with increased odds of DD in the univariate analysis, using the 2017 algorithm (OR, 1.68; $P=.013)$, although the $P$ value was slightly higher than .05 in the multivariable analysis (Table 3 ).

\section{DISCUSSION}

In this cross-sectional study using a community-based cohort of asymptomatic individuals without known cardiovascular disease, 
Table 3

Association Between Blood Pressure Categories and Diastolic Function Parameters

\begin{tabular}{|c|c|c|c|c|c|c|}
\hline & \multicolumn{3}{|c|}{ Univariable analysis } & \multicolumn{3}{|c|}{ Multivariable analysis } \\
\hline & $\beta$ coefficient & SE & $P$ & $\beta$ coefficient & SE & $P$ \\
\hline \multicolumn{7}{|l|}{ E'velocity } \\
\hline Optimal & Reference & & & Reference & & \\
\hline Prehypertension & -0.94 & 0.30 & .002 & -0.56 & 0.27 & .035 \\
\hline Hypertension & -2.58 & 0.27 & $<.001$ & -1.08 & 0.26 & $<.001$ \\
\hline \multicolumn{7}{|l|}{ E/E' ratio } \\
\hline Optimal & Reference & Refer & & & & \\
\hline Prehypertension & 0.31 & 0.24 & .206 & 0.24 & 0.23 & .289 \\
\hline \multirow[t]{2}{*}{ Hypertension } & 1.61 & 0.22 & $<.001$ & 0.78 & 0.23 & .001 \\
\hline & Odds ratio & SE & $P$ & Odds ratio & SE & $P$ \\
\hline \multicolumn{7}{|l|}{ Diastolic dysfunction } \\
\hline \multicolumn{7}{|c|}{2016 joint ASE/EACVI recommendations } \\
\hline Optimal & Reference & & & Reference & & \\
\hline Prehypertension & 3.25 & 5.05 & .448 & 2.47 & 3.88 & .566 \\
\hline Hypertension & 5.90 & 8.68 & .227 & 2.42 & 3.68 & .561 \\
\hline \multicolumn{7}{|c|}{2017 clinically-oriented algorithm } \\
\hline Optimal & Reference & & & Reference & & \\
\hline Prehypertension & 1.68 & 0.35 & .013 & 1.48 & 0.33 & .080 \\
\hline Hypertension & 4.31 & 0.84 & $<.001$ & 2.47 & 0.53 & $<.001$ \\
\hline
\end{tabular}

ASE/EACVI, American Society of Echocardiography/European Association of Cardiovascular Imaging; SE, standard error.

In the multivariable analyses, age, sex, body mass index, and the presence of diabetes were included in the model, in addition to the blood pressure categories assessed in each regression equation. All multivariable models showed McFadden's R-squared between 0.2-0.4, therefore providing good-fit models.

Table 4

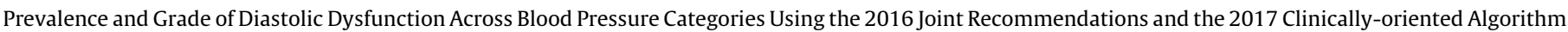

\begin{tabular}{|c|c|c|c|c|c|c|c|c|}
\hline & \multicolumn{3}{|c|}{2016 ASE/EACVI Joint Recommendations } & \multicolumn{5}{|c|}{2017 Clinically-Oriented Algorithm } \\
\hline & \multirow[b]{2}{*}{ Normal } & \multirow[b]{2}{*}{ DD } & \multirow[b]{2}{*}{ Indeterminate } & \multicolumn{2}{|c|}{ Diastolic function } & \multicolumn{3}{|c|}{ LV filling pressures } \\
\hline & & & & Normal & DD & Likely normal & Indeterminate & Likely elevated \\
\hline \multicolumn{9}{|l|}{ BP category } \\
\hline Optimal & $165(95.9)$ & $0(0.0)$ & $7(4.1)$ & $124(72.1)$ & $48(27.9)$ & $57(71.2)$ & $22(27.5)$ & $1(1.2)$ \\
\hline Prehypertension & $254(90.4)$ & $2(0.8)$ & $25(8.9)$ & $170(60.5)$ & $111(39.5)$ & $118(70.2)$ & $42(25.0)$ & $8(4.8)$ \\
\hline Hypertension & $364(77.1)$ & $6(1.3)$ & $102(21.6)$ & $176(37.3)$ & $296(62.7)$ & 169 (49.6) & $132(38.7)$ & $40(11.7)$ \\
\hline
\end{tabular}

ASE/EACVI, American Society of Echocardiography/European Association of Cardiovascular Imaging; BP, blood pressure; DD, diastolic dysfunction; LV, left ventricle.

Data are expressed as No. (\%).

we found a continuous association between the deterioration of diastolic function and BP levels, including SBP, DBP, and PP. More importantly, we observed that although diastolic function impairment is more pronounced in hypertensive individuals, these changes were already present in prehypertensive individuals, reflecting subclinical organ damage in this population.

\section{Impairment of Diastolic Function in Prehypertensive Individuals}

There is currently strong evidence supporting a continuum of cardiovascular risk in function of BP values, not exclusive to the hypertensive range. ${ }^{11,12,17}$ This relationship was highlighted in a meta-analysis of 61 prospective studies, which showed a strong relationship between cardiovascular mortality and BP values, down to BP values of $115 / 75 \mathrm{mmHg} .{ }^{17}$ Also, previous studies have shown that prehypertensive individuals have more target-organ damage than normotensive individuals, namely vascular damage. ${ }^{22,23}$

In our study we showed a continuous relationship between increasing degrees of BP (especially SBP and DBP) and a deterioration in E' velocity, suggesting impaired cardiac relaxation. This observation supports the notion that these changes may reflect the cumulative effect of hypertension on the myocardium. ${ }^{6}$ Moreover, we observed that prehypertensive individuals had significantly lower E' velocities compared with patients with "optimal BP", showing that changes in diastolic function are already present in the prehypertensive stage. These results are in agreement with a previously published study based on an analysis from the ARIC cohort ${ }^{18}$ comprising a sample of 4871 older individuals (mean age 75 years), showing a progressive impairment of diastolic function parameters throughout different BP thresholds (from optimal BP to hypertension). Although there were significant differences between the groups in terms of diastolic function parameters (e' lateral, E/e' lateral) and prevalence of DD, there were no differences in systolic function parameters.

In our study, PP was associated with a higher E/e' ratio and left atrial volume index (denoting increased left ventricle filling pressure), and with increased odds of DD. PP is an indirect index of arterial stiffness and an independent predictor of cardiovascular mortality. ${ }^{24}$ Data from the Framingham Heart Study provide support that in middle-aged and elderly individuals, PP has more prognostic power for cardiovascular events than SBP or DBP, ${ }^{25}$ and identifies the highest-risk patients for developing heart failure. ${ }^{26}$ Increased arterial stiffness might increase left ventricle hypertrophy due to cardiac pressure overload, therefore contributing to the morphological and functional changes involved in the pathophysiology of DD and elicit subclinical cardiac damage. 
Our data corroborate the sensitivity of diastolic function parameters as markers of myocardial subclinical organ damage in this clinical setting. From a pathophysiological standpoint, several mechanisms might account for the progressive deterioration of cardiac relaxation and increased myocardial stiffness ${ }^{27}$ : increased fibrosis, hypophosphorylation of titin, altered myocardial metabolism, decreased nitric oxide availability and a proinflammatory milieu.

\section{The Role of Diastolic Function as a Target Organ in Cardiovascular Risk Assessment}

The presence of DD, even when subclinical, is considered an independent predictor of cardiovascular events and mortality. ${ }^{7}$ For example, in hypertensive individuals from the ASCOT substudy, the $\mathrm{E} / \mathrm{e}$ ' ratio was an independent predictor of cardiovascular events. ${ }^{6}$ Curiously, most E/e' ratio values were within the normal range, reflecting that this is indeed a sensitive parameter. Even in hypertensive patients with left ventricular hypertrophy, which is an established marker of target organ damage, ${ }^{3}$ impairment of diastolic function parameters adds prognostic information, allowing a better assessment of risk in this population. ${ }^{28}$

In our study, we decided to include 2 different criteria to define DD: the 2016 ASE/EACVI Joint Recommendations ${ }^{15}$ and a recently published clinically-oriented algorithm. ${ }^{16}$ The former replaced the previous recommendations for echocardiographic assessment of diastolic function. ${ }^{21}$ However, it has been strongly criticized because it was not validated and because its " $50 \%$ rule" is very stringent, resulting in a large proportion of patients being included as "indeterminate" group ( $14.5 \%$ in our study). Indeed, according to the 2016 Joint Recommendations, we found a prevalence of DD of $0.9 \%$, markedly different from the $49.2 \%$ using the 2017 algorithm and $22.0 \%$ using the previous recommendations from 2009 (Table of the supplementary material). This prevalence of DD is in line with a recently published study using data from 1485 participants of the community-based STANISLAS cohort (1.3\%). ${ }^{29}$ The small number of cases of DD using the 2016 criteria might account for the lack of significant association in the multivariable analysis both with prehypertension and hypertension. On the other hand, using the 2017 clinically-oriented algorithm, hypertensive patients had a 2.47 increased odds of DD and prehypertension was associated with a 1.48 increased odds of DD $(P=.080)$. Given the importance of DD in the interface between hypertension and the development of $\mathrm{BP},{ }^{4,30}$ our findings offer a possible explanation for the increased cardiovascular risk in prehypertensive individuals. ${ }^{31}$

\section{Strengths and Limitations}

The strengths of this study include the assessment of a relatively large sample of the general population, without other cardiac diseases, using contemporary echocardiographic techniques for the assessment of diastolic function. ${ }^{21}$ In this study, which comprised individuals 45 years or older, the prevalence of hypertension was $53.6 \%$, which is similar to that reported in European individuals aged between 35 and 64 years (44.2\%), ${ }^{32}$ and for Portuguese individuals between 35 and 64 years (46.9\%). ${ }^{33}$ Diastolic function was evaluated according to the recommendations of the consensus document of the European Association of Echocardiography and the American Society of Echocardiography, ${ }^{21}$ which recommend the evaluation of E' velocities and E/E' ratio from tissue Doppler. In this study, we observed a stronger association between BP parameters and E' velocity, which is considered an early and preload-independent index of left ventricular relaxation, ${ }^{28}$ whereas the E/E' ratio is used to estimate increased left ventricle filling pressures. ${ }^{34}$

In this study, most patients were female (63\%) and we adopted a cross-sectional design, which partially limits comments on causality. Furthermore, among the 2048 cohort members within the eligible age range, 580 individuals (28\%) were unreachable by telephone or post. Although we excluded patients with clinical signs of coronary artery disease, we did not perform any stress tests to exclude myocardial ischemia, which is also a determinant of DD. In the assessment of diastolic function, we did not evaluate intraobserver or interobserver variability. However, all 4 cardiologists had extensive experience in echocardiography and worked in the same institution and a detailed procedure protocol was discussed between the team, prior to the start of the study, to harmonize the methodology and the measurements. Regarding the logistic regression models, due to the small number of positive cases of DD using some of the definitions, maximum likelihood estimation of conventional logistic model may suffer from small-sample bias. To address this problem, as well as the risk of over-adjustment after forcing 4 variables in the multivariable model (age, sex, body mass index, and diabetes), we used Firth-type penalized likelihood logistic regression analysis. Finally, in this study, all BP measurements were obtained using office BP, and not with ambulatory BP monitoring, which is currently the gold-standard method recommended in hypertension guidelines and provides a more accurate approach to the relationship between cardiovascular morbidity and mortality than office BP. ${ }^{3}$ The use of ambulatory BP monitoring would potentially result in the reclassification of some individuals in a lower BP category. ${ }^{35}$

\section{CONCLUSIONS}

In this large sample of the general population, there was a continuous relationship between BP levels and deterioration of diastolic function parameters. Changes in diastolic function were already present in prehypertensive individuals, reflecting myocardial subclinical organ damage in this population. Given the prognostic impact of DD in hypertensive patients, these observations reinforce the importance of assessing diastolic function in the workup of both hypertensive and prehypertensive patients.

\section{CONFLICTS OF INTEREST}

None declared.

\section{WHAT IS KNOWN ABOUT THE TOPIC?}

- Hypertension is a major cardiovascular risk factor that is associated with structural and functional deleterious cardiac changes, contributing to impaired diastolic function and heart failure with preserved ejection fraction. Few studies have specifically evaluated the association between prehypertension and DD, especially considering the recent 2016 updated recommendations for the evaluation of diastole.

\section{WHAT DOES THIS STUDY ADD?}

- Using a community-based cohort free of known cardiovascular disease, we found a continuous relationship between BP levels and deterioration of diastolic function parameters. Furthermore, prehypertensive individuals seemed to have an increased odds of DD using both the 2016 ASE/EACVI Joint Recommendations and a 2017 clinically-oriented algorithm. Our findings emphasize the importance of assessing diastolic function in the workup of both hypertensive and prehypertensive patients 


\section{APPENDIX A. SUPPLEMENTARY MATERIAL}

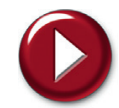

Supplementary material associated with this article can be found in the online version available at: http://dx.doi. org/10.1016/j.rec.2017.11.015.

\section{REFERENCES}

1. Poulter NR, Prabhakaran D, Caulfield M. Hypertension. Lancet. 2015;386:801-812.

2. Sehestedt T, Jeppesen J, Hansen TW, et al. Risk prediction is improved by adding markers of subclinical organ damage to SCORE. Eur Heart J. 2010;31:883-891.

3. Mancia G, Fagard R, Narkiewicz K, et al. 2013 ESH/ESC Practice Guidelines for the Management of Arterial Hypertension. Blood Press. 2014;23:3-16.

4. Lip GY, Felmeden DC, Li-Saw-Hee FL, Beevers DG. Hypertensive heart disease. A complex syndrome or a hypertensive'cardiomyopathy'? Eur Heart J. 2000;21:1653-1665.

5. Bountioukos M, Schinkel AF, Bax JJ, Lampropoulos S, Poldermans D. The impact of hypertension on systolic and diastolic left ventricular function. A tissue Doppler echocardiographic study. Am Heart J. 2006;151:1323.e7-e12.

6. Sharp AS, Tapp RJ, Thom SA, et al. Tissue Doppler E/E' ratio is a powerful predictor of primary cardiac events in a hypertensive population: an ASCOT substudy. Eur Heart J. 2010;31:747-752.

7. Redfield MM, Jacobsen SJ, Burnett Jr JC, Mahoney DW, Bailey KR, Rodeheffer RJ. Burden of systolic and diastolic ventricular dysfunction in the community: appreciating the scope of the heart failure epidemic. JAMA. 2003;289:194-202.

8. Fontes-Carvalho R, Goncalves A, Severo M, et al. Direct, inflammation-mediated and blood-pressure-mediated effects of total and abdominal adiposity on diastolic function: EPIPorto study. Int J Cardiol. 2015;191:64-70.

9. Yousaf F, Collerton J, Kingston A, et al. Prevalence of left ventricular dysfunction in a UK community sample of very old people: the Newcastle $85+$ study. Heart 2012;98:1418-1423.

10. Fontes-Carvalho R, Ladeiras-Lopes R, Bettencourt P, Leite-Moreira A, Azevedo A Diastolic dysfunction in the diabetic continuum: association with insulin resistance, metabolic syndrome and type 2 diabetes. Cardiovasc Diabetol. 2015;14:4.

11. Wan SH, Vogel MW, Chen HH. Pre-clinical diastolic dysfunction. J Am Coll Cardiol. 2014;63:407-416.

12. Kane GC, Karon BL, Mahoney DW, et al. Progression of left ventricular diastolic dysfunction and risk of heart failure. JAMA. 2011;306:856-863.

13. Mogelvang R, Sogaard P, Pedersen SA, et al. Cardiac dysfunction assessed by echocardiographic tissue Doppler imaging is an independent predictor of mortality in the general population. Circulation. 2009;119:2679-2685.

14. Marwick TH, Gillebert TC, Aurigemma G, et al. Recommendations on the use of echocardiography in adult hypertension: a report from the European Association of Cardiovascular Imaging (EACVI) and the American Society of Echocardiography (ASE). Eur Heart J Cardiovasc Imaging. 2015;16:577-605.

15. Nagueh SF, Smiseth OA, Appleton CP, et al. Recommendations for the Evaluation of Left Ventricular Diastolic Function by Echocardiography: An Update from the American Society of Echocardiography and the European Association of Cardiovascular Imaging. Eur Heart J Cardiovasc Imaging. 2016;17:1321-1360.

16. Mitter SS, Shah SJ, Thomas JD. A Test in Context: E/A and E/e' to Assess Diastolic Dysfunction and LV Filling Pressure. J Am Coll Cardiol. 2017;69:1451-1464.

17. Lewington S, Clarke R, Oizilbash N, Peto R, Collins R; Prospective Studies Collaboration. Age-specific relevance of usual blood pressure to vascular mortality: a meta-analysis of individual data for one million adults in 61 prospective studies. Lancet. 2002;360:1903-1913.
18. Santos AB, Gupta DK, Bello NA, et al. Prehypertension Is Associated With Abnormalities of Cardiac Structure and Function in the Atherosclerosis Risk in Communities Study. Am J Hypertens. 2016;29:568-574

19. Perkiomaki JS, Mottonen M, Lumme J, Kesaniemi YA, Ukkola O, Huikuri HV. Predictors of Development of Echocardiographic Left Ventricular Diastolic Dysfunction in the Subjects Aged 40 to 59 Years (from the Oulu Project Elucidating Risk of Atherosclerosis Study). Am J Cardiol. 2015;116:1374-1378.

20. Lang RM, Badano LP, Mor-Avi V, et al. Recommendations for cardiac chamber quantification by echocardiography in adults: an update from the American Society of Echocardiography and the European Association of Cardiovascular Imaging. Eur Heart J Cardiovasc Imaging. 2015;16:233-270.

21. Nagueh SF, Appleton CP, Gillebert TC, et al. Recommendations for the evaluation of left ventricular diastolic function by echocardiography. Eur J Echocardiogr. 2009;10:165-193.

22. Ikram MK, Witteman JC, Vingerling JR, Breteler MM, Hofman A, De Jong PT. Retinal vessel diameters and risk of hypertension: the Rotterdam Study. Hypertension. 2006;47:189-194

23. Tenekecioglu E, Yilmaz M, Yontar OC, et al. Microalbuminuria in untreated prehypertension and hypertension without diabetes. Int J Clin Exp Med. 2014;7:34203429.

24. Benetos A, Rudnichi A, Safar M, Guize L. Pulse pressure and cardiovascular mortality in normotensive and hypertensive subjects. Hypertension. 1998;32: 560-564.

25. Franklin SS, Khan SA, Wong ND, Larson MG, Levy D. Is pulse pressure useful in predicting risk for coronary heart Disease? The Framingham heart study. Circulation. 1999;100:354-360.

26. Haider AW, Larson MG, Franklin SS, Levy D, Framingham Heart S. Systolic blood pressure, diastolic blood pressure, and pulse pressure as predictors of risk for congestive heart failure in the Framingham Heart Study. Ann Intern Med. 2003:138:10-16.

27. Messerli FH, Rimoldi SF, Bangalore S. The Transition From Hypertension to Heart Failure: Contemporary Update. JACC Heart Fail. 2017;5:543-551.

28. Wang M, Yip GW, Wang AY, et al. Tissue Doppler imaging provides incrementa prognostic value in patients with systemic hypertension and left ventricular hypertrophy. J Hypertens. 2005;23:183-191.

29. Huttin O, Fraser AG, Coiro S, et al. Impact of Changes in Consensus Diagnostic Recommendations on the Echocardiographic Prevalence of Diastolic Dysfunction.J Am Coll Cardiol. 2017;69:3119-3121.

30. Verma A, Solomon SD. Diastolic dysfunction as a link between hypertension and heart failure. Med Clin North Am. 2009;93:647-664.

31. Guo X, Zhang X, Guo L, et al. Association between pre-hypertension and cardiovascular outcomes: a systematic review and meta-analysis of prospective studies. Curr Hypertens Rep. 2013;15:703-716.

32. Wolf-Maier K, Cooper RS, Banegas JR, et al. Hypertension prevalence and blood pressure levels in 6 European countries, Canada, and the United States. JAMA. 2003;289:2363-2369.

33. Polonia J, Martins L, Pinto F, Nazare J. Prevalence, awareness, treatment and control of hypertension and salt intake in Portugal: changes over a decade. The PHYSA study. J Hypertens. 2014;32:1211-1221.

34. Ommen SR, Nishimura RA, Appleton CP, et al. Clinical utility of Doppler echocardiography and tissue Doppler imaging in the estimation of left ventricular filling pressures: A comparative simultaneous Doppler-catheterization study. Circulation. 2000; $102: 1788-1794$.

35. Gorostidi M, Sobrino J, Segura J, et al. Ambulatory blood pressure monitoring in hypertensive patients with high cardiovascular risk: a cross-sectional analysis of a 20,000-patient database in Spain. J Hypertens. 2007;25:977-984. 